\title{
Study of Performance and Environmental Emissions of a Gasoline Spark Ignition Engine
}

\section{Mehrnoosh Dashti $^{{ }^{*}}$, Ali Asghar Hamidi ${ }^{\mathrm{b}}$, Ali Asghar Mozafaric}

a Department of Mechanical Engineering, Central Tehran Branch, Islamic Azad University, Niayesh Complex, Oorg Blv., Poonak Square, Tehran, Iran.

${ }_{b}$ Department of Chemical Engineering, University of Tehran, Enghelab Ave., Teharan, Iran.

School of Mechanical Engineering, Sharif University of TechnologyAzadi Ave., Teharan, Iran.

Received: March 21, 2013/ Accepted: April 16, 2013

\begin{abstract}
There are concerns both about the excess usage of limited fossil fuels reservoirs, and the environmental emissions production of fossil fuels such as $\mathrm{CO}, \mathrm{CO}_{2}, \mathrm{NO}_{\mathrm{x}}$, UHC and particles which may have long term effects on sustainable development and providing welfare and convenience for future generations. Internal combustion engines have caused the largest contribution to these problems. The most common internal combustion engines are gasoline engines which cannot be replaced completely from vehicle fleets due to technical benefits. In this study, a spark ignition engine cycle simulation based on the first law of thermodynamics has been developed. The model effectively described the thermodynamic processes and chemical state of the working fluid by considering a closed cycle containing compression, combustion, ignition delay and expansion processes. The two-zone model was used for simulation of the combustion process and the species including $\mathrm{CO}_{2}, \mathrm{CO}, \mathrm{H}_{2} \mathrm{O}, \mathrm{H}_{2}, \mathrm{~N}_{2}, \mathrm{O}_{2}, \mathrm{NO}$ and $\mathrm{UHC}$ were considered as exhaust gases. The model predicted the trends and tradeoffs of the engine performance characteristics including indicated power, IMEP, ISFC and emissions. Finally, the model has been used to carry out a parametric study of the engine to evaluate the effects of a number of engine parameters. This analysis showed the capability of the model to predict engine performance characteristics over the various ranges of engine parameters.
\end{abstract}

Keywords: Engine, Gasoline, Simulation, Performance, Emission

Corresponding Author

Tel.: +982144600037; Fax.: +982144600067;meh.dashti@ iauctb.ac.ir
Abbreviations and Subscripts:

\begin{tabular}{|c|c|c|}
\hline A & : & Area \\
\hline $\mathrm{aBDC}$ & $:$ & after BDC \\
\hline aTDC & $:$ & after TDC \\
\hline bBDC & $:$ & before BDC \\
\hline bTDC & $:$ & before TDC \\
\hline B & $:$ & Cylinder bore, $[\mathrm{m}]$ \\
\hline $\mathrm{BDC}$ & $:$ & Bottom Dead Centre \\
\hline C & $:$ & Carbon atom \\
\hline CR & $:$ & Compression Ratio \\
\hline $\mathrm{CO}$ & : & Carbon Monoxide \\
\hline $\mathrm{CO}_{2}$ & $:$ & Carbon Dioxide \\
\hline $\mathrm{D}$ & $:$ & Length, [m] \\
\hline EVC & $:$ & Exhaust Valve Close \\
\hline EVO & $:$ & Exhaust Valve Open \\
\hline Expt. & $:$ & Experiment \\
\hline $\mathrm{H}$ & : & Hydrogen atom \\
\hline $\mathrm{H}_{2}$ & : & Hydrogen gas \\
\hline $\mathrm{H}_{2} \mathrm{O}$ & : & Water Vapor \\
\hline IMEP & : & Indicated Mean Effective Pressure \\
\hline ISFC & $:$ & $\begin{array}{lll}\text { Indicated } & \text { Specific } & \text { Fuel } \\
\text { Consumption } & & \end{array}$ \\
\hline IVC & : & Inlet Valve Close \\
\hline IVO & $:$ & Inlet Valve Open \\
\hline $\mathrm{K}$ & : & $\begin{array}{l}\text { Thermal conductivity of the } \\
\text { mixture, }\left(W \cdot m^{-1} \cdot K^{-1}\right)\end{array}$ \\
\hline MFB & : & Mass Fraction Burned \\
\hline MBT & : & Maximum Brake Torque \\
\hline $\mathrm{N}$ & : & Cylinder moles, [mole] \\
\hline $\mathrm{N}$ & : & Engine speed, [RPS] \\
\hline $\mathrm{N}_{2}$ & : & Nitrogen \\
\hline $\mathrm{NO}$ & : & Nitrogen Oxide \\
\hline $\mathrm{O}$ & : & Oxygen atom \\
\hline $\mathrm{O}_{2}$ & : & Oxygen gas \\
\hline $\mathrm{P}$ & : & Pressure, [Pas] \\
\hline PPM & : & Parts Per Million \\
\hline $\mathrm{R}$ & $:$ & $\begin{array}{l}\text { Ratio of connection rod length to } \\
\text { crank radius }\end{array}$ \\
\hline $\mathrm{R}$ & : & Flame radius, $[\mathrm{cm}]$ \\
\hline $\operatorname{Re}$ & : & Reynolds number \\
\hline Rpm & : & Revolution per minute \\
\hline ST & : & Spark Timing [degree] \\
\hline $\mathrm{T}$ & : & Temperature, [K] \\
\hline $\mathrm{T}$ & : & Time, $[\mathrm{s}]$ \\
\hline TDC & $:$ & Top Dead Center \\
\hline $\mathrm{U}$ & : & Flame speed, [m/s] \\
\hline $\mathrm{UHC}$ & $:$ & Unburned Hydrocarbons \\
\hline V & $:$ & Volume, $\left[\mathrm{m}_{3}\right]$ \\
\hline W & $:$ & Work [J] \\
\hline WOT & $:$ & Wide Open Throttle \\
\hline$P_{0}$ & : & Atmospheric pressure,[bar] \\
\hline$C_{v}$ & $:$ & $\begin{array}{l}\text { Specific heat capacity at constant } \\
\text { volume, }\left[\mathrm{J} . \mathrm{kg}^{-1} \cdot \mathrm{K}^{-1}\right]\end{array}$ \\
\hline$K_{t}$ & $:$ & Flame factor \\
\hline
\end{tabular}




\begin{tabular}{lll|}
$\theta \theta$ & $:$ & Crank angle, [radian] \\
$\dot{q}$ & $:$ & Heat Transfer Flux, $[\mathrm{W} / \mathrm{m} 2]$ \\
$R$ & $:$ & Universal gas constant, $\left.^{-1} \cdot \mathrm{J}^{-1}\right]$ \\
$\Phi$ & $:$ & Equivalence Ratio \\
Subscripts: & $:$ & \\
1 & $:$ & Initial state of the interval \\
2 & $:$ & Final state of the interval \\
$\mathrm{B}$ & $:$ & Burned gas \\
$\mathrm{F}$ & $:$ & Flame \\
$\mathrm{G}$ & $:$ & Gas \\
$\mathrm{L}$ & $:$ & Laminar \\
$\mathrm{M}$ & $:$ & Number of hydrogen in the fuel \\
$\mathrm{N}$ & & formula \\
$\mathrm{T}$ & $:$ & Number of carbon in the fuel \\
$\mathrm{U}$ & & formula \\
$\mathrm{W}$ & $:$ & Tubular \\
$\mathrm{X}$ & $:$ & Unburned gas \\
& $:$ & Wall \\
& $:$ & Number of oxygen in the fuel \\
& & formula
\end{tabular}

\section{Introduction}

The energy crisis is one of the important issues which attract a lot of concern in human societies, especially with world energy consumption increasing considerably. As the main resource of energy in the world is fossil fuels, energy consumption growth not only decreases available energy reservoirs but also increases environmental emissions. If the pollutants are not controlled considerably, there may be harmful effects on human health, living beings and societies. Also, there are expected concerns both about the excess usage of limited fossil fuels reservoirs, and the environmental emissions produced by fossil fuels such as $\mathrm{CO}$, $\mathrm{CO}_{2}, \mathrm{NO}_{\mathrm{X}}, \mathrm{UHC}$ and particles which may have long term effects on sustainable development and providing welfare and convenience for future generations.

Between various consumers of fossil fuels, motor vehicles produce around $15 \%$ of global fossil fuel $\mathrm{CO}_{2}$ releases [1] and of this, the largest contribution belongs to internal combustion engines.

The most common internal combustion engines are gasoline engines which are used more in road transportation. In spite of making efforts for complete replacement of gasoline engines with alternative fuels in automobiles, the gasoline engines cannot be replaced completely from the vehicle fleets. The lack of an alternative fuel with the ability of gasoline engine performance and the impossibility of rapid change in the infrastructure of the automobile industry has led to gasoline remaining as a main fuel in automobiles.

In this context, the basis of new alternative fuelled engine technology of internal combustion engines is very similar to gasoline engines. The analysis of gasoline engines can be considerable in regards to the technical and environmental aspects.

Over the years, the use of simulation codes to model the thermodynamic cycle of an internal combustion engine have developed into tools for more efficient engine designs and fuel consumption. The simulation models are valuable economically as cost effective tools for the parametric study of engine operations. G. H. Alla [2] simulated the engine cycle of a four stroke engine and proposed an arbitrary heat release formula to predict the heat transfer in the engine. He investigated the effect of some engine operating conditions on the engine performance characteristics. The results from the model have been checked with measured data. J. A. Caton [3] developed a thermodynamic simulation of the SI engine cycle. He studied the performance, energy and availability characteristics of the engine by using multiple zones for the combustion process. Also, he investigated the effect of compression ratio on nitric oxide emissions [4].

The combustion of SI engines itself is an extremely complex phenomena and many models have been developed with different levels of complexity and ability to simulate the combustion processes. In the simplest approach, the zero-dimensional model is used to predict combustion processes in the cylinder. However, the engine cannot conduct combustion at constant volume, i.e. instantaneously at TDC, because a real burning process takes time, the piston keeps moving and the cylinder volume changes. If this latter problem could be remedied by keeping the piston stationary at TDC while combustion took place and then moving it down the power stroke when all is burned, the Indicated Mean Effective Pressure (IMEP) and power would increase by some 50\% [2]. In the quasi-dimensional model the entire cylinder contains two zones, burned and unburned. Obviously, this model is more accurate than that of a zero-dimensional model. In other models, the entire combustion chamber is taken to be three zones: unburned zone, adiabatic burned zone, and a boundary layer burned zone [5]. In this work the two - zone combustion model is applied for the combustion simulation. A first and second law analysis of a real spark ignition engine cycle has been developed by Rakopoulos [6]. He used an advanced one zone model for the combustion process and evaluated the engine characteristic parameters. The validation of the thermodynamical analysis of the cycle was done by comparing with the experimental results. R. S. Benson and co-workers [7] developed a simulation model for a single cylinder four stroke cycle spark ignition engine. They simulated a full engine cycle consisting of gas exchange processes with $\mathrm{NO}$ emissions. They used two-zone model for modeling the flame front propagation in the cylinder. A good agreement between the predicted and measured $\mathrm{NO}$ over a range of equivalence ratios considered was noted.

In the present work, a spark ignition engine cycle simulation based on the first law of thermodynamic has been developed by stepwise calculations for compression process, ignition delay time, combustion and expansion processes. The building blocks of the model are mass and energy conservation equations. Equations cannot be solved analytically and Newton-Raphson method was used to solve the equations numerically. The two-zone model was used to simulate the combustion process. The burned gas zone and unburned gas zone are separated by a thin flame front and the flame front propagates spherically throughout the combustion chamber.

The model effectively describes the thermodynamic processes and chemical state of the working fluid via a closed system containing compression, ignition delay, combustion, and expansion processes. The model predicts the trends and tradeoffs by theoretical thermodynamically based analysis of the spark ignition to determine the performance characteristics over a wide range of design and operating variables. Experimental data are also presented to indicate the validity of the model. The predicted results based on the model have shown reasonable agreement with the corresponding experimental data.

\section{Thermodynamic modeling of the engine cycle}

The basis of the thermodynamic modeling is the first law of thermodynamics. The compression, ignition delay, combustion and expansion processes are divided into small intervals. In every interval, a small volume change occurs corresponding to crank 
angle rotation. The total internal energy before and after each interval is balanced to calculate variations of temperature, pressure, work and heat transfer to the cylinder wall. More accurate calculations are obtained using smaller changes in the interval.

In the model, the work is approximated by:

$$
\Delta W=\left(\frac{P_{1}+P_{2}}{2}\right) \times\left(V_{2}-V_{1}\right)
$$

$\Delta W$ denotes work change in the interval. Also, the convective and radiative heat transfer rate has been predicted with empirical correlation equation proposed by Annaned [8]. The heat transfer rate from cylinder gas to the wall is calculated as:

$$
\dot{q}=\overbrace{a\left(\frac{k}{D}\right) \operatorname{Re}^{b}\left(T_{g}-T_{w}\right)}^{\text {Convection Heat Transfer }}+\overbrace{c\left(T_{g}{ }^{4}-T_{w}{ }^{4}\right)}^{\text {Radiation }} \text { Heat Transfer }
$$

The value of coefficient a varies between 0.35 and 0.8 with respect to the charge motion intensity and engine design. The value of $\mathrm{b}$ is 0.7 , and $\mathrm{c}$ is $0.429 \times 10^{-8}\left(\mathrm{~W} /\left(\mathrm{m}^{2} . \mathrm{K}^{4}\right)\right.$ for spark ignition engines. The heat transfer area is considered as:

$$
A=A_{\text {cylinder head }}+A_{\text {cylinder periphery }}+A_{\text {pistoncrossection }}
$$

that,

$$
\begin{aligned}
& A_{\text {cylinder head }}+A_{\text {piston cross section }}=\frac{\pi}{2} B^{2} \\
& A_{\text {cylinder periphery }}=\frac{\pi B L}{2}\left(R+1-\cos \theta-\sqrt{R^{2}-\sin ^{2} \theta}\right)
\end{aligned}
$$

The heat transfer from piston face area has been ignored. The time interval has been expressed as:

$$
\Delta t=\frac{\Delta \theta}{2 \pi \times N}
$$

\subsection{Compression and expansion strokes}

In every interval of the compression and expansion strokes, the initial gas temperature and pressure of the compression are defined. The first guess for temperature at the end of each interval may be obtained by assuming an isentropic change from the initial state.

Then, the first estimation is evaluated by the first law of thermodynamics and corresponding to the error in the equation ( error $\left.=E_{2}-E_{1}+\Delta W-\Delta Q\right)$, temperature is corrected by Newton - Raphson formula:

$$
T_{2, \text { new }}=T_{2, \text { old }}-\left(\frac{\text { error }}{n_{2}\left(T_{2, \text { old }}\right) \times C_{v}\left(T_{2, \text { old }}\right)}\right)
$$

The old and new subscripts denote the first guess and the modification of temperature, respectively. The reference for calculation of specific heat capacity at constant volume as a function of temperature is [8]. The pressure at the end of each interval can be obtained by considering the state equation of the ideal gases as following:

$$
P_{2}=P_{1}\left(\frac{V_{1}}{V_{2}}\right)\left(\frac{T_{2}}{T_{1}}\right)\left(\frac{n_{2}\left(T_{2}\right)}{n_{1}\left(T_{1}\right)}\right)
$$

Then, the first law of thermodynamic is examined for new values of $T$ and $P$. In every interval, the calculation is repeated until the first law of thermodynamics is satisfied with the required accuracy. It is obvious that during the compression, the composition of the cylinder gas is considered constant, but, in the expansion stroke, the composition is changed in every interval due to dissociation reactions.

\subsection{Ignition delay and combustion process}

In the quasi-dimensional combustion model, the cylinder is divided into two zones separated by a thin flame front. The flame front propagates spherically throughout the combustion chamber to the point that it contacts the cylinder wall and head. Therefore the volume of burned zone and mass fraction burned in each step is determined by cylinder geometry. Cylinder contents are assumed to be ideal gases and the equation of state is employed. The laminar flame speed is calculated from an empirical expression for propane-air mixture [7], which has been used in this work:

$$
U_{I}=\left[\frac{7784}{\left(\frac{10000}{T_{b}}+\frac{900}{T_{u}}\right)^{4.938}}\right]\left(\frac{P_{0}}{P}\right)^{0.09876}
$$

A number of other laminar flame theories have been given in other reference [8]. The relationship between the turbulent flame speed and laminar flame speed is modelled as:

$$
U_{t}=K_{t} \times U_{l}
$$

$K_{t}$ is the flame factor which is obtained by the following expression:

$$
K_{t}=1+b \times r p m
$$

where $\mathrm{b}$ is a constant between 0.0017 and 0.0020 and is related to the type of engine and turbulence. The best approximation of the value of $K_{t}$ can be obtained by comparing the simulated pressure-time diagram with the experimental data. The flame radius variation has been calculated by $[7]$ :

$$
\Delta r_{f}=\frac{U_{t} \times \Delta \theta}{360 \times N}
$$

Once the flame volume has exceeded o.oor of the total volume, the compression stroke has finished and the flame is assumed to appear. After initiation of the combustion stroke, the following simulation steps have been used in the modeling of the flame propagation in the cylinder at the combustion process: (1) compression of burned zone and unburned zone with inclusion of heat and work transfer, (2) combustion of a thin layer of the unburned zone and formation of a new burned zone, (3) temperature equalization of new burned zone and old burned zone and (4) pressure equalization in the whole of cylinder.

\subsection{Emissions}

The combustion products and exhaust gases include seven species, $\mathrm{CO}_{2}, \mathrm{CO}, \mathrm{H}_{2} \mathrm{O}, \mathrm{H}_{2}, \mathrm{~N}_{2}, \mathrm{O}_{2}$, NO and $\mathrm{UHC}$. The following 
four equilibrium reactions have been considered to obtain the equilibrium distribution of products:

$$
\begin{gathered}
\mathrm{CO}+\frac{1}{2} \mathrm{O}_{2} \leftrightarrow \mathrm{CO}_{2} \\
\mathrm{CO}+\mathrm{H}_{2} \mathrm{O} \leftrightarrow \mathrm{CO}_{2}+\mathrm{H}_{2} \\
n \mathrm{CO}_{2}+\mathrm{m} / 2 \mathrm{H}_{2} \leftrightarrow \mathrm{C}_{n} \mathrm{H}_{m} \mathrm{O}_{x}+(n-x / 2) \mathrm{O}_{2} \\
1 / 2 \mathrm{~N}_{2}+1 / 2 \mathrm{O}_{2} \leftrightarrow \mathrm{NO}
\end{gathered}
$$

By considering conservation of the atomic mass of $\mathrm{O}, \mathrm{H}, \mathrm{N}$ and $\mathrm{C}$ (four equations) and using the equilibrium constants method for equilibrium reactions (four above equations), the concentrations or molar fractions of the eight mentioned species can be obtained. Newton-Raphson method is used as a numerical method for solving equations to finally converge to a solution. Also, the Zeldovitch mechanism was used for non-equilibrium NO formation.

\section{Results and Discussion}

\subsection{Experimental data}

All tests were performed in the engine testing laboratory of Irankhodro Powertrain Company (IPCO). A $\mathrm{XU}_{7} \mathrm{JP} / \mathrm{L}_{3}$ four cylinder research spark ignition engine is used in this research. Technical specifications of the engine are given in Table 1 . The engine is made to run at various ranges of speed at Wide Open Throttle (WOT) conditions. Gasoline composition with research octane number of 95.7 is used in the test with mass percentages of carbon 85.55 , hydrogen 13.74 and oxygen 0.71 .

Table 1 Engine specifications

\begin{tabular}{ll}
\hline Item & Specification \\
\hline Engine Type & $\mathrm{XU}$ JP/L3 \\
Number of Cylinder & 4 \\
Bore [mm] & 83 \\
Stroke [mm] & 81.4 \\
Con. Rod length [mm] & 143.1 \\
Load (\%) & 100 \\
Equivalence Ratio [ $\Phi]$ & 1.1 \\
Speed [rpm] & $1500-4500$ \\
Spark Timing [ST] & MBT \\
Compression Ratio [CR] & 9.2 \\
IVO [deg] & 8.5 bTDC \\
IVC [deg] & 29.3 aBDC \\
EVO [deg] & 43.3 bBDC \\
EVC [deg] & 5.6 aTDC \\
\hline
\end{tabular}

\subsection{Model Validation}

Experimental data are presented to indicate validity of the developed thermodynamical model. The performance characteristics of the engine including indicated power, IMEP, (Indicated Specific Fuel Consumption) ISFC and emissions are compared with corresponding experimental results.

\subsubsection{Pressure and Temperature of the Cylinder Contents}

Figure 1 shows the variation of cylinder pressure with respect to crank angle at $3000 \mathrm{rpm}$ at WOT. According to the Figure 1, the predicted pressure change has good agreement with experimental results. In the simulation, the predicted pressure - crank angle diagram is compared with the experimental pressure data to obtain the proper tubular flame speed and the flame factor of the cylinder contents. For the conditions considered, there is a difference in the peak pressure. This is due to the fact that misfiring and crevice effects have not been considered in the simulation but in fact both phenomena exist in experimental findings and lower the peak pressure.

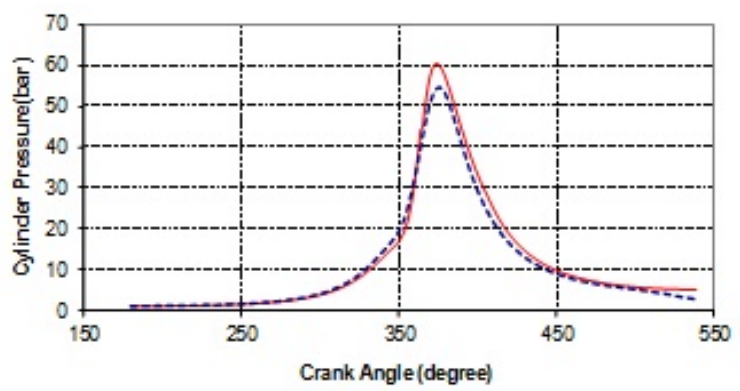

Figure 1 Cylinder pressure versus crank angle ( $\Phi:$ 1.1, CR: 9.2, ST: 16 bTDC, $3000 \mathrm{rpm}$ and WOT (Model :- Experimental data :- - - ))

The variation of cylinder temperature versus crank angle at 3000 rpm at WOT is shown in Figure 2. The trends of temperature change for unburned $(\mathrm{Tu})$ and burned $(\mathrm{Tb})$ zones are consistent with the literature [7-9].

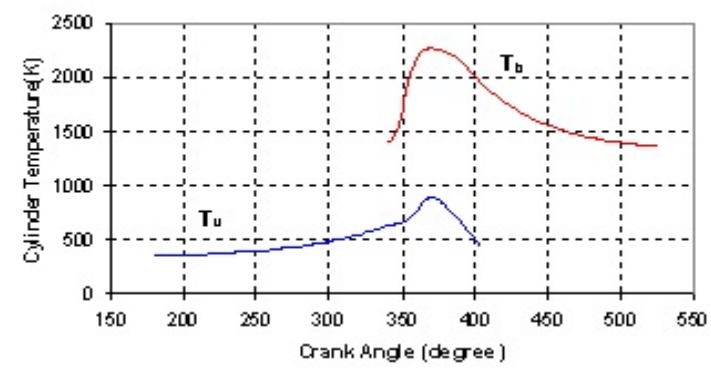

Figure 2 Cylinder temperature versus crank angle ( $\Phi: 1.1, C R:$ 9.2, ST: 16 bTDC, $3000 \mathrm{rpm}$ and WOT)

\subsubsection{Indicated power and IMEP}

Figure 3 shows the engine indicated power and IMEP in the range of $1500-4000$ rpm engine speed.
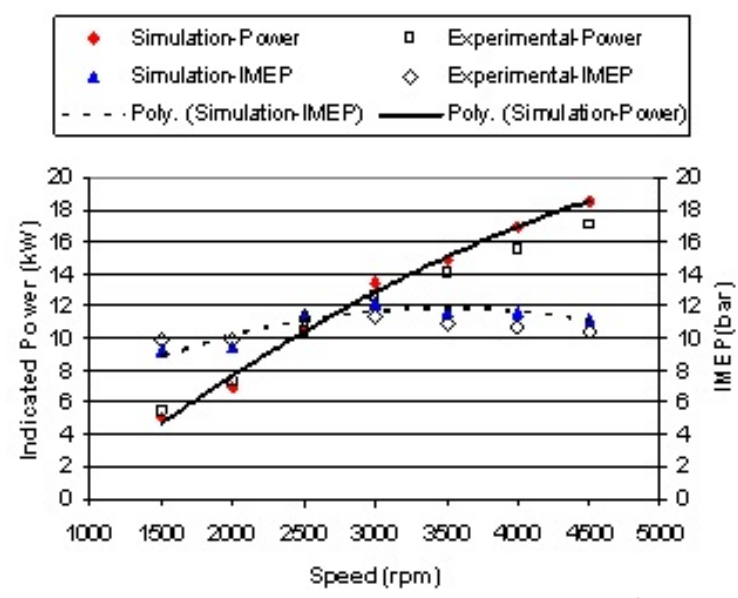

Figure 3 Indicated power and IMEP versus engine speed (Ф:1.1, CR: 9.2, ST: 16 bTDC and WOT (Model :- , Experimental data : $\bullet, \bullet)$ )

According to Figure 3, the values and trends of the predicted power and IMEP coincide with the experimental data. The engine indicated power is increased as speed of the engine is increased due to increases in the number of cycles per time. 


\subsubsection{Fuel consumption}

The fuel consumption of the engine at various engine speeds is shown in Figure 4. It is found that higher ISFC is obtained at higher engine speeds. When the engine runs at high speed, it consumes more fuel to obtain higher power. The predicted results based on the model show reasonable agreement with the corresponding experimental data.

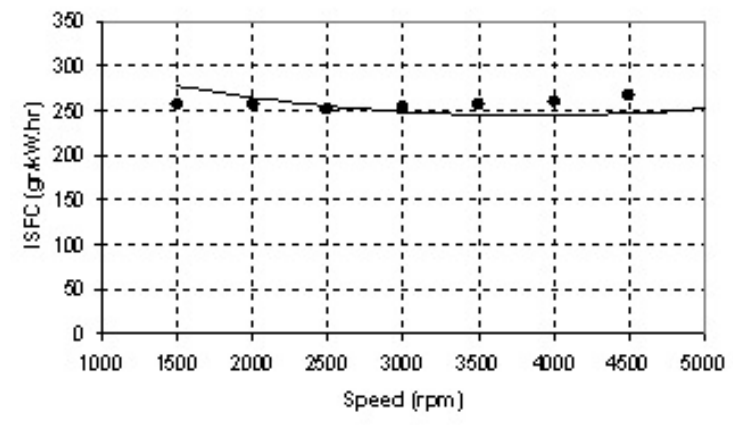

Figure 4 ISFC versus Engine Speed (Ф: 1.1, CR: 9.2, ST: 16 bTDC and WOT (Model: - , Experimental data : $\bullet$ ))

\subsubsection{Emissions}

Table 2 and 3 shows the $\mathrm{CO}_{2}, \mathrm{CO}$, NO and UHC (unburned Hydro Carbons) concentration in the exhaust gases at various speeds. According to these tables, emissions predicted by model have good agreement with corresponding experimental results. Since the effects of crevices in the engine have not been included in the theoretical model, the predicted results for UHC concentration are lower than that of the experimental data.

Table 2 Prediction of $\mathrm{CO}_{2}$ and $\mathrm{CO}$ Emissions at various engine speeds

\begin{tabular}{lllll}
\hline \multirow{2}{*}{ Speed (rpm) } & \multicolumn{2}{l}{ CO2 $(\%$ volume ) } & \multicolumn{2}{l}{ CO (\%volume ) } \\
\cline { 2 - 5 } & Model & Expt. & Model & Expt. \\
\hline $\mathbf{1 5 0 0}$ & 12.52 & 13.05 & 3.81 & 2.97 \\
$\mathbf{2 0 0 0}$ & 12.50 & 13.02 & 3.78 & 2.78 \\
$\mathbf{2 5 0 0}$ & 12.47 & 13.01 & 3.73 & 2.67 \\
3000 & 12.44 & - & 3.90 & - \\
3500 & 12.49 & - & 3.81 & - \\
$\mathbf{4 0 0 0}$ & 12.49 & - & 3.85 & - \\
\hline
\end{tabular}

Table 3 Prediction of UHC and NO Emissions at various engine speeds

\begin{tabular}{lrrrc}
\hline \multirow{2}{*}{ Speed (rpm) } & UHC $(\mathbf{p p m})$ & \multicolumn{3}{c}{ NO (ppm) } \\
\cline { 2 - 5 } & Model & Expt. & Model & Expt. \\
\hline $\mathbf{1 5 0 0}$ & 648 & 2779 & 1195 & 1369 \\
$\mathbf{2 0 0 0}$ & 1325 & 1908 & 1208 & 1135 \\
$\mathbf{2 5 0 0}$ & 1252 & 1766 & 1324 & 1469 \\
3000 & 1397 & - & 1395 & - \\
$\mathbf{3 5 0 0}$ & 1313 & - & 1536 & - \\
$\mathbf{4 0 0 0}$ & 1509 & - & 1635 & - \\
\hline
\end{tabular}

\subsection{Parametric study}

According to previous section, the model shows good agreement with experimental data. Therefore, the model is a good tool to study the performance characteristics of the engine over a range of operating variables.

\subsubsection{Effects of Equivalence Ratio}

Equivalence ratio is an operating variable which affects performance and fuel consumption of the engine. Figure 5 illustrates the variation of the engine indicated power and IMEP for equivalence ratios in the range of 0.8 to 1.3. It is seen that the maximum power and IMEP are obtained at equivalence ratio of about 1.1 due to more complete combustion than at other equivalence ratios.

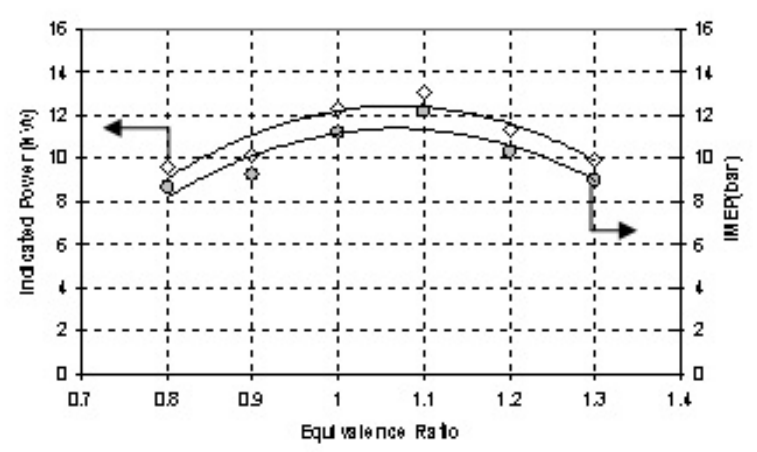

Figure 5 Indicated Power and IMEP versus equivalence ratio, CR: 9.2, ST: 16 bTDC, $3000 \mathrm{rpm}$ and WOT

The effect of equivalence ratio on ISFC and combustion duration is presented in Fig. 6. Obviously, the higher fuel consumption is obtained with increasing equivalence ratio. In the higher equivalence ratio the cylinder mixture will be richer. As expected, the combustion is most efficient in the equivalence ratio of 1.1 and therefore the duration of combustion to release the fuel energy is minimum. Therefore as it can be seen in Figure 6, the predicted combustion duration is decreased when the equivalence ration is near to 1.1 .

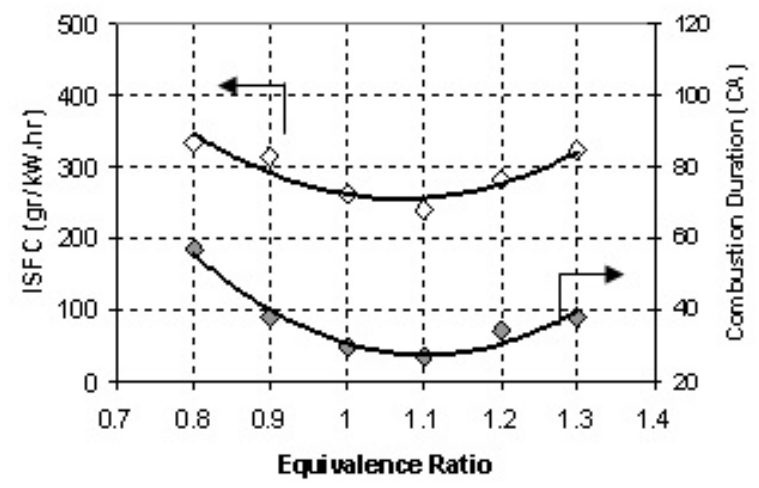

Figure 6 ISFC and Combustion Duration versus Equivalence Ratio, CR: 9.2, ST: 16 bTDC, 3000 rpm and WOT

The burning rate of fuel is an important combustion characteristic that approximately reflects the rate of cumulative heat release in the combustion process. The simulation model predicts the mass fraction burned (MFB) by considering burned zone volume in each step versus equivalence ratio, shown in the Figure 7 . The burning rate of fuel is maximum at the equivalence ratio of 1.1 as a result of faster flame propagation.

In fact, operating at lean or rich mixtures the MFB is decreased. This is because of oxygen deficiency and incomplete combustion on the rich side of the equivalence ratio. On the lean side of the equivalence ratio, the low temperature of the flame is the main reason for MFB reduction. So, the flame temperature is low at rich and lean mixtures resulting in the slope of the curve for $\Phi=1.1$ being the highest. It is notable that the variation of equivalence ratio has considerable effect on the rate of burning and heat release as expected. As shown in Figure 7, the slowest rate of burning belongs to $\Phi=0.8$ at which the temperature of the flame is the lowest. 


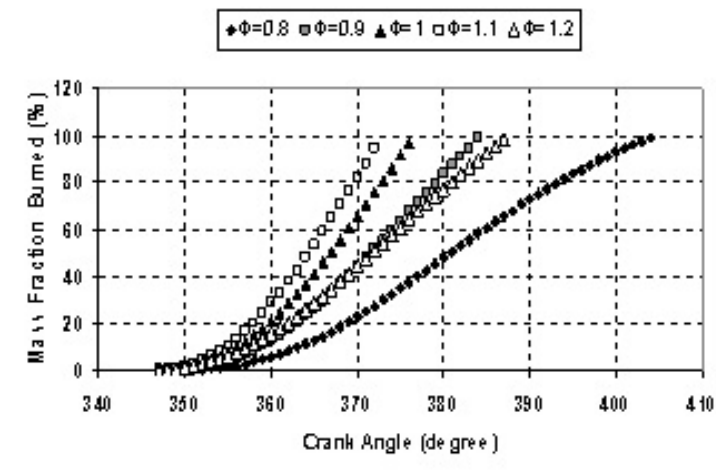

Figure 7 Mass Fraction Burned versus Equivalence Ratio, CR:9.2, ST: 16 bTDC, $3000 \mathrm{rpm}$ and WOT

\subsubsection{Effects of Compression Ratio}

In Figure 8 the indicated power and IMEP is plotted with respect to compression ratio. Both indicated power and IMEP increase with increasing compression ratio. The power rises by $18 \%$ for compression ratio of 7 to 11 .

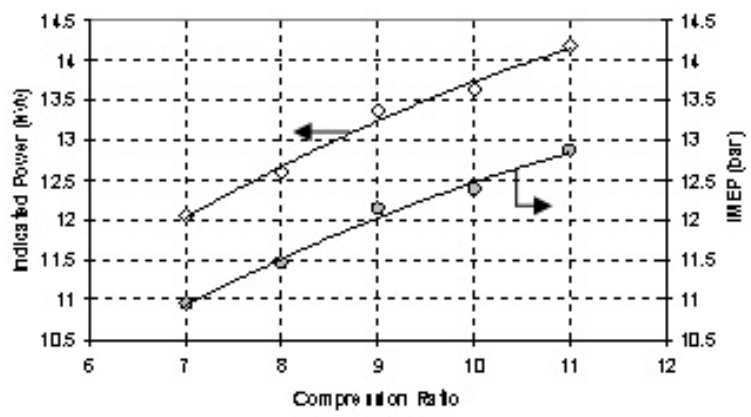

Figure 8 Indicated Power and IMEP versus Compression Ratio, $\Phi: 1.1$, ST: $16 \mathrm{bTDC}, 3000 \mathrm{rpm}$ and WOT

The effect of compression ratio on ISFC and combustion duration is shown in Figure 9. The ISFC is decreased by $15 \%$ for a change of compression ratio from 7 to 11 . Also, the combustion duration is reduced in this range from 30 degrees to 27 degrees. This is due to the fact that when the pressure of the cylinder content is increased; the combustion process occurs more efficiently and therefore the ignition delay decreases.

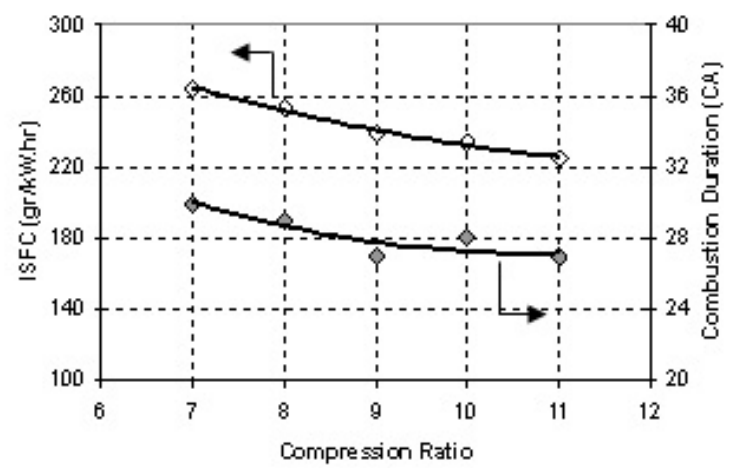

Figure 9 ISFC and Combustion Duration versus Compression Ratio $\Phi:$ 1.1, ST: 16 bTDC, $3000 \mathrm{rpm}$ and WOT

The effect of compression ratio increase on the MFB is presented in Figure 10. In this figure, the MFB is increased for higher compression ratios due to better combustion and higher fuel energy release rate.

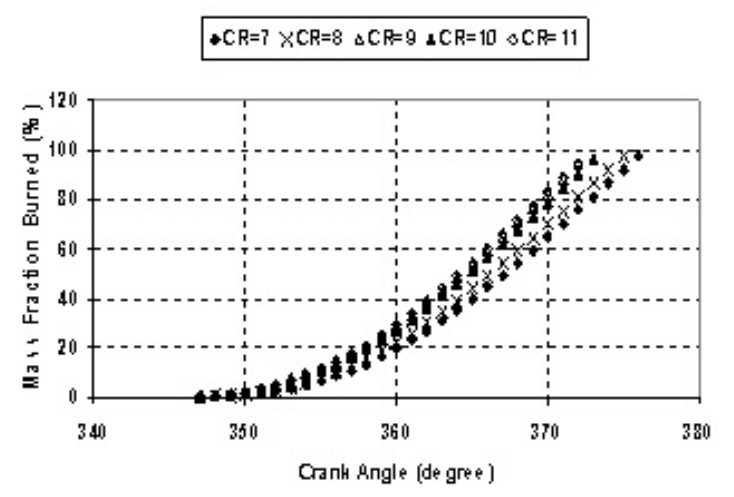

Figure 1o Mass Fraction Burned versus Compression Ratio Ф:1.1, ST: 16 bTDC, $3000 \mathrm{rpm}$ and WOT

\subsubsection{Effects of Spark Timing}

In the SI engine, if ignition is too early, work will be wasted in the compression stroke. On the other hand, if ignition occurs too late, the indicated power is lower due to lower peak pressure of combustion. So, there is an optimum timing for spark for which the maximum torque is obtained. This timing is called Maximum Brake Torque (MBT). It is clear that the indicated power and IMEP is maximum at 16 bTDC (MBT timing). These trends are shown in Figure 11.

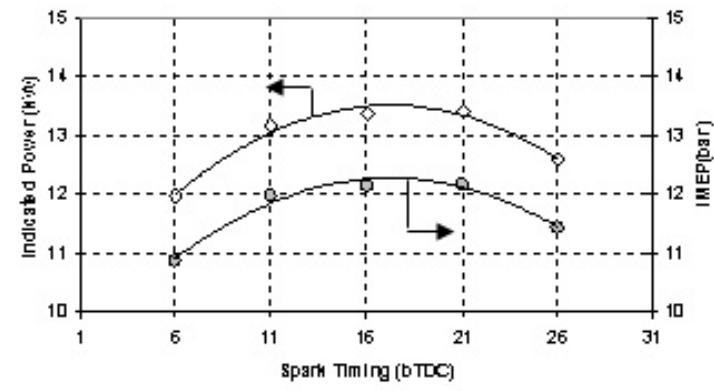

Figure 11 Indicated Power and IMEP versus Spark Timing, $\Phi: 1.1$, CR: 9.2, $3000 \mathrm{rpm}$ and WOT

In Figure 12 the variation of ISFC and combustion duration with respect to spark timing is seen. According to this figure, the ISFC is minimum at MBT. At this point, the power is maximum according to Figure 8. As expected, at less or more than MBT spark timing, the fuel consumption is increased due to power decreasing. This trend is also seen for the combustion duration. As expected, the shortest combustion duration belongs to MBT advance spark timing.

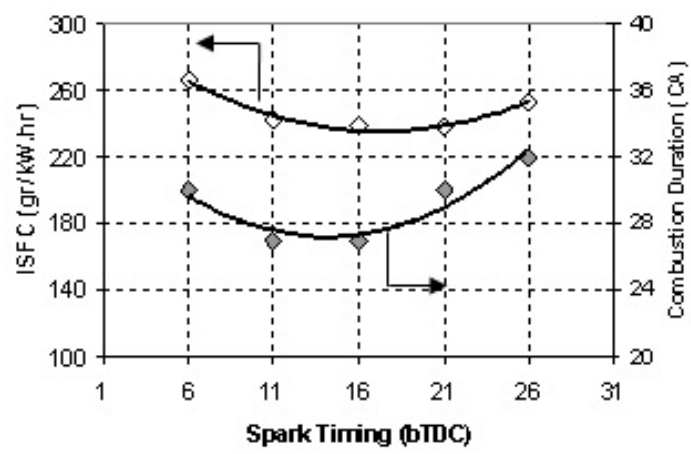

Figure 12 ISFC and Combustion Duration versus Spark Timing, $\Phi:$ 1.1, CR: 9.2, $3000 \mathrm{rpm}$ and WOT

Referring to Figure 13, the rate of mass burning is decreased if the spark timing is retarded. This is because of decreasing 
temperature of cylinder content and as a result the reduction of flame speed propagation.

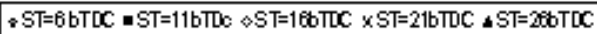

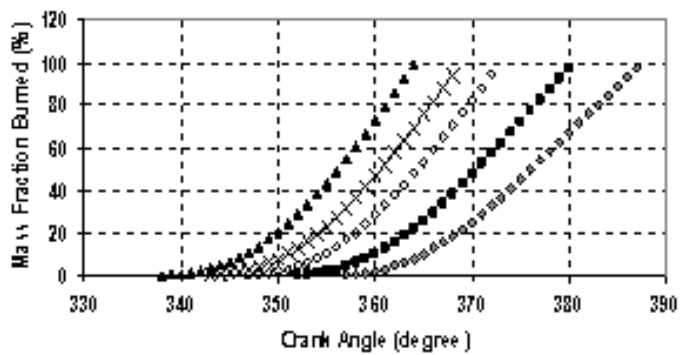

Figure 13 Mass Fraction Burned versus Spark Timing, $\Phi: 1.1$, CR: 9.2, 3000 rpm and WOT

\section{Conclusions}

In this study, a thermodynamic cycle simulation model for a conventional four-stroke gasoline SI engine has been developed. The model is primarily based on the first law of thermodynamics. The simulated cycle was a closed cycle which included compression, ignition delay, combustion and expansion processes. A two-zone model for the combustion process simulation has been used. The performance characteristics and emissions concentration of SI gasoline engine are predicted by the model. To check the validity of the model, the theoretical results were compared with the corresponding experimental results. It is found that the simulated results show reasonable agreement with the experimental data. Parametric studies have been carried out for investigation of the equivalence ratio, compression ratio and spark timing effects on the engine performance. Within the context of sustainability, such models could be utilised for application with alternative fuels or to predict and improve the emissions from conventional fuels.

\section{Acknowledgements}

The authors wish to thank the laboratory for engine testing at IPCO for the experimental data and IFCO for the financial support.

\section{References}

[1] http://www.wri.org/publication/content/8468.

[2] Alla AGH. Computer simulation of a four stroke spark ignition engine. Energy Conversion and Management 2002; 43:1043-1061.

[3] Caton JA. A cycle simulation including the second law of thermodynamics for the spark-ignition engines: implications of the use of multiple-zones for combustion. SAE paper 2002; 2002-01-007.

[4]Caton JA. Effects of the compression ratio on nitric oxide emissions for a spark ignition engine: results from a thermodynamic cycle simulation. Int J Engine Res 2003; 4(4):249-268.

[5] Pathak D. Use of thermodynamic cycle simulation to determine the difference between a propane-fuelled engine and an iso-octane-fuelled engine. M. Sc. Thesis, Texas A \& M University, United States; 2005.

[6] Rakopoulos CD. Evaluation of a spark ignition engine cycle using first and second law analysis techniques. Energy Conversion and Management 1993; 34(12):1299-1314.

[7]Benson RS, Annand WJD, Baruatt PC. A simulation model including intake and exhaust system for a single cylinder four-stroke cycle spark ignition engine. Int J Mech Sci 1975; 17:97-124.
[8]Heywood JB. Internal Combustion Engine Fundamentals, New York, Mc Graw-Hill Inc; 1988.

[9] Olivier LC, Frédéric P. NOx emissions reduction of a natural gas SI engine under lean conditions: comparison of the EGR and RGR concepts, Proceedings of ICES20o6 Spring Technical Conference of the ASME Internal Combustion Engine Division, Aachen, Germany; 2004. 